\title{
Laparoscopic colorectal surgery is safe and may be beneficial in patients eighty years of age and over
}

\author{
Mathew A. Kozman*, Daniel R. Kozman
}

Department of Colorectal Surgery, St George Hospital, Kogarah, Australia

Email: "makozman@gmail.com

Received 22 November 2011; revised 31 December 2011; accepted 26 March 2012

\begin{abstract}
Objective: To establish that the laparoscopic approach to colorectal resection is safe with regards to postoperative morbidity and mortality in patients eighty years of age and over. Methods: Prospectively collected data for consecutive patients aged eighty years and older who underwent laparoscopic colorectal resection by the same surgeon (Dr. Daniel R. Kozman) from 1st January 2009 till 31st March 2011, were retrospectively analysed. Data collected included baseline demographic information, operative indication, American Society of Anaesthesiologists (ASA) grading, procedure type, length of procedure, post-operative course, length of hospital stay, discharge destination and complications. Results: Thirty-one patients underwent laparoscopic colectomy during the study period, 28 for adenocarcinoma. The median age was 85.5 (range 80 - 92) years, 15 patients were male and 25 patients were from home. The mean operating time was 118.4 minutes (range 45 - 271). Conversion was required in only 4 of 31 cases $(13 \%)$. The mortality rate was $10 \%$ in total, and $0 \%$ in elective cases. Three patients required re-operation, 2 of which initially presented in the emergency setting and were subsequently deceased. For survivors, the length of hospital stay was 8.1 days (range 3 - 30) with $100 \%$ returning to original place of residence. Conclusion/ Interpretation: Laparoscopic surgery in patients eighty years and over is safe and may be beneficial in the elective setting. This is evident by low complication rate, fast return to bowel function, short length of hospital stay, and likely return to pre-operative place of residence and low mortality rate in elective patients. Careful consideration should be given to its use in an emergency setting.
\end{abstract}

Keywords: Laparoscopic; Colectomy; Colorectal; Surgery

*Corresponding author.

\section{INTRODUCTION}

In the last few decades, laparoscopic surgery has become much more readily available and accepted for performing colorectal resection. Nowadays, most colorectal procedures may be performed laparoscopically.

Laparoscopic-assisted colonic resection has been shown to be safe and effective in several large multicentre randomised control trials. It provides significant improvements in return of gastrointestinal function and length of hospital stay, with no difference in the complication rate. When applied for the purpose of oncological colonic resection, it produced similar histological parameters and rates of cancer recurrence when compared with open colectomy [1-5]. In addition to this, collective reviews and appraisals of the literature confer several short-term benefits of laparoscopic colorectal surgery when compared to the open approach. These include reduced blood loss, less intensive post-operative pain, shorter length of hospital stay, reduced and shorter post-operative ileus rate and reduced wound infection rate [6-8].

In the last decade, there have been an increasing number of studies addressing the role of laparoscopic surgery for colorectal resection in the elderly population, all showing favourable results [9-11]. Fewer studies address the benefit in patients eighty years of age and older, though still indicate that this surgical technique is safe and effective [12-15].

According to the Australian Bureau of Statistics, Australia is an aging population and as such, the proportion of the population comprising of those eighty years of age and over is projected to continue to greatly increase. As such, the profession is seeing an increasing number of patients eighty years of age and over presenting with colorectal disease both electively and in the emergency setting.

The authors of this study recognise the importance of return to pre-operative function in this patient group. As such, the current study was designed to review the safety of laparoscopic colorectal resection with regards to postoperative morbidity and mortality in this patient group. 


\section{PATIENTS AND METHODS}

All data were prospectively collected from 1st January 2009 till 31st March 2011.

The charts, electronic medical records, anaesthetic records and operating room databases of patients recruited were retrospectively analysed to acquire data regarding patient demographics, the operation and post-operative course.

\subsection{Patient Selection}

Consecutive patients aged eighty years or older who underwent laparoscopic colorectal resection by the same surgeon (Dr Daniel R. Kozman) from 1st January 2009 till 31st March 2011were included in the study.

\subsection{Preoperative Preparation and Operative Considerations}

The same principle surgeon, aided by one camera assistant, conducted all operations. All patients were analysed on an intention to treat basis.

All patients received general anaesthesia and $1 \mathrm{~g}$ of a third generation cephalosporin (Cephazolin or Ceftriaxone) and metronidazole $500 \mathrm{mg}$ intravenously.

For right-sided resections, the colon was mobilised laparoscopically and vessels divided intracorporeally. The anastomosis was performed extracorporeally. For leftsided resections, the colon was mobilised laparoscopically, and vessels divided intracorporeally. The rectum was mobilised either laparoscopically or through a pfannenstiel incision as a hybrid operation.

Conversion was defined as an incision required for mobilisation of the colon or division of vessels.

\subsection{Measured Outcomes}

Data collected included baseline demographic information (including pre-operative place of residence), indication for operation, American Society of Anaesthesiologists (ASA) grading, type of procedure, length of procedure, post-operative course (time to passing flatus, opening bowels, oral fluid intake and oral solid intake), length of hospital stay, discharge destination and complications (including return to theatre and return to hospital).

Comorbidity factors on hospital admission were assessed according to the American Society of Anaesthesiologists (ASA) score.

\section{RESULTS}

During the study period, laparoscopic colorectal resection was attempted in 31 patients aged eighty years and older. The mean age was 85.5 years (range 80 - 92), and of the 31 patients, 15 (48\%) were male. Preoperatively anaesthesiologist assessment showed that American Society of Anaesthesiologists (ASA) grade varied from grade 2 to 4 , with $58 \%$ of patients being deemed grade 3 , thus possessing moderate to severe systemic disease. Fifteen of the 31 patients (48\%) had undergone previous abdominal surgery of various nature. The majority of patients underwent a colectomy for colorectal cancer (90\%). One patient had perforated diverticular disease, 1 had recurrent volvulus and 1 had recurrent diverticulitis. Nine of the 31 operations were conducted in the emergency setting (Table 1).

Twenty patients underwent a right or extended righthemicolectomy representing $65 \%$ of operations performed. In addition, 7 anterior resections, 1 left hemicolectomy, 1abdomine perineal resection, 1 Hartmanns procedure and 1 combination of a right hemicolectomy and anterior resection were performed. Four patients required conversion to an open procedure giving a conversion rate of $13 \%$. Three of these were converted due to presence of dense adhesions from previous abdominal surgery, while the last was converted due to a colorectal lymphoma of greater than $15 \mathrm{~cm}$ in diameter. Average surgical operation time was 118.4 minutes (range 45 - 271). No intraoperative complications occurred in this series (Table 2).

Table 1. Patient characteristics.

\begin{tabular}{lc}
\hline \multicolumn{1}{c}{ Variable } & No. of Patients \\
\hline Age (years) & Mean: 85.5 (Range: 80 - 92) \\
Gender & \\
- Male & $15(48 \%)$ \\
- Female & $16(52 \%)$ \\
Place of Residence: & \\
- Home & $25(80 \%)$ \\
- Hostel & $2(7 \%)$ \\
- Nursing Home & $4(13 \%)$ \\
American Society of Anaesthesiologists & \\
(ASA) Score-Systemic Disease: & \\
- 2-Mild & $6(19 \%)$ \\
- 3-Moderate to Severe & $18(58 \%)$ \\
- 4-Severe & $7(23 \%)$ \\
Previous Abdominal Surgery & $15(48 \%)$ \\
Indication & \\
- Adenocarcinoma & $28(90 \%)$ \\
- Perforation (Diverticular) & $1(3 \%)$ \\
- Volvulus & $1(3 \%)$ \\
- Diverticular Disease & $1(3 \%)$ \\
Setting & \\
- Elective & $22(71 \%)$ \\
- Emergency & $9(29 \%)$ \\
\hline
\end{tabular}


Table 2. Operative characteristics.

\begin{tabular}{lc}
\hline \multicolumn{1}{c}{ Variable } & No. of Patients \\
\hline Type of Laparoscopic Resection & \\
- Left Hemicolectomy & $1(3 \%)$ \\
- Right or Extended Right Hemicolectomy & $20(65 \%)$ \\
- Anterior Resection/Sigmoid Colectomy & $7(23 \%)$ \\
- Abdominoperineal Resection & $1(3 \%)$ \\
- Hartmann’s Procedure & $1(3 \%)$ \\
- Right Hemicolectomy + Anterior Resection & $1(3 \%)$ \\
Operation Time (minutes) & Mean: 118.4 \\
Conversion to Open & (Range: 45 - 271) \\
\hline
\end{tabular}

The mean time to passing of flatus and opening of bowels was 3.1 days (range 1 - 5) and 4.6 days (range 1 10) days respectively. Mean time to commencement of solid diet was 3.8 days (range 1 - 10). Three of the 31 patients died throughout the postoperative course, all of which has undergone an operation in the emergency setting. This represents a mortality rate of $10 \%$. One of these underwent a palliative laparoscopic Hartmann's procedure for a perforated stent, and subsequently died on day 10 after withdrawal of treatment. One patient underwent an anterior resection for recurrent sigmoid volvulus, subsequently sustaining a postoperative bleed followed by an anastomotic leak. The final patient, was on home oxygen due to type II respiratory failure, and died of his respiratory disease following an anastomotic leak post emergency laparoscopic right hemicolectomy for a bleeding caecal tumor. The remaining 28 patients all returned to their original place of residence. The average length of hospital stay for these patients was 8.1 days (range 3 - 30). Three patients were required to be taken back to the operating theatre, 2 for post-operative bleeding, and one for an anastomotic leak. Two of these patients subsequently died as described above. Five patients experienced minor complications not requiring extensive treatment, these were urinary tract infection, superficial wound infection, transient atrial fibrillation, small incisional hernia and sinus bradycardia (Table 3).

\section{DISCUSSION}

Several large multicentre randomised control trials have shown laparoscopic colorectal surgery to be safe and effective [1-5]. Furthermore, the literature confers that these benefits also apply to the elderly population [9-11]. There are only limited trials in the literature addressing the advantages of a laparoscopic approach to performing colectomy in patients eighty year of age and over, however these suggest that this surgical technique is safe and effective [12-15]. As these patients are a fast-growing
Table 3. Post-operative characteristics.

\begin{tabular}{lc}
\hline \multicolumn{1}{c}{ Variable } & No. of Patients \\
\hline $\begin{array}{l}\text { For survivors, time (days) to: } \\
\text { - Flatus }\end{array}$ & Mean: 3.1 (Range: 1 - 5) \\
- Bowels opened & Mean: 4.6 (Range: 1 - 10) \\
- Commencement of diet & Mean: 3.8 (Range: 1 - 10) \\
$\begin{array}{l}\text { For survivors, length of hospital stay } \\
\text { (days) }\end{array}$ & Mean: 8.1 (Range: 3 - 30) \\
$\begin{array}{lc}\text { Return to original place of residence } \\
\text { For survivors, complications-Within 30 } \\
\text { days: }\end{array}$ \\
$\begin{array}{l}\text { - Minor complications } \\
\text { - Return to operating theatre }\end{array}$ \\
$\begin{array}{l}\text { - Return to hospital } \\
\text { Deceased }\end{array}$ \\
\hline
\end{tabular}

segment of the Australian population, the profession is seeing an increasing number of patients from this age group presenting with colorectal disease both electively and in the emergency setting, making this a topic of intense relevance.

Kurian et al. [12], compared outcomes for octogenarians undergoing colectomy. 139 open and 150 laparoscopically. While Lian et al. [13] compared the same with 97 patients in each arm of the study matched 1:1. These two American trials showed similar results with regards to short-term morbidity, conferring the several short-term benefits. In both studies, the laparoscopic group was associated with a shorter mean length of hospital stay (7 and 6 days respectively), and with a mortality rate of $2 \%$ and $5.2 \%$ respectively. The percentage of patients discharged home was $79 \%$ in both studies. It is worth noting that both these studies excluded all patients requiring emergency colectomy.

Cheung et al. [14] attempted laparoscopic colorectal cancer resection in 101 octogenarians. The overall morbidity and operative mortality rate were $17 \%$ and $3 \%$ respectively. In addition, this trial also concluded that the long-term oncological outcomes and survival figures were favourable.

Jayne et al. [5] recently published their Five-year follow-up of the Medical Research Council CLASICC trial of laparoscopically assisted versus open surgery for colorectal cancer. The 5-year analyses confirm the oncological safety of laparoscopic surgery for both colonic and rectal cancer, hence emphasizing that the use of laparoscopic surgery to maximize short-term outcomes does not compromise the long-term oncological results.

The current study, although comprised of a smaller number of patients, demonstrates that laparoscopic colectomy is safe and may provide short-term benefits. This is 
evident in the short operation time, low complication rate, prompt return to bowel function and short length of hospital stay.

It is worth noting that only 2 of the 31 cases exceeded 165 minutes, one being conducted in the emergency setting. In addition, only 2 of the 28 patients who survived the post-operative course had a length of hospital stay greater than 13 days, one had her hospital stay lengthened to 18 days for management of new onset atrial fibrillation, and the other was taken back to the operating theatre for post-operative bleeding as described earlier.

In this study, 3 of the 31 patients died throughout the postoperative course, representing a mortality rate of $10 \%$. However, all of these patients underwent an operation in the emergency setting. Thus the mortality rate in the elective setting was $0 \%$, which is marked improvement on previous studies available.

A recent study showed that advancing age and postoperative complications are associated with the risk of discharge to a nursing facility after abdominopelvic operations [16]. However, in this series, $100 \%$ of patients who underwent an elective procedure and $100 \%$ of the 28 survivors were discharged to their original pre-operative place of residence. Of these 24 of the 28 patients were from home.

The higher morbidity and mortality in the emergency setting better reflect the nature of the patients' condition rather than the nature of the surgery.

These figures provide notable improvements when compared with older studies, most likely reflecting ongoing advancement in laparoscopic surgical technique and instrumentation, the experience of the surgical team and stringent patient selection. In addition, this explains the low conversion rate of $13 \%$ and complete absence of intra-operative complications.

Our results demonstrate the safety and potential shortterm benefits of laparoscopic colectomy for patients eighty years of age and over, and our findings are comparable to previous studies addressing this topic. This is especially true for those patients undergoing their procedure in the elective setting. Nonetheless, further large multicentre trials are necessary to reinforce this.

\section{CONCLUSION}

Laparoscopic surgery in patients eighty years of age and over is safe and may be beneficial in the elective setting. This is evident by low complication rate (intra-operative and post-operative), fast return to bowel function, short length of hospital stay, likely return to pre-operative place of residence and low mortality rate in elective patients. Careful consideration should be given to its use in an emergency setting.

\section{REFERENCES}

[1] Hewett, P.J., Allardyce, R.A., Bagshaw, P.F., Frampton,
C.M., Frizelle, F.A., Rieger, N.A., Smith, J.S., Solomon, M.L., Stephens, J.H. and Stevenson, A.R.L. (2008) Shortterm outcomes of the Australasian randomized clinical study comparing laparoscopic and conventional open surgical treatments for colon cancer: The ALCCaS trial. Annals of Surgery, 248, 728-738.

[2] Guillou, P.J., Quirke, P., Thorpe, H., Walker, J., Jayne, D.G., Smith, A.M.H., Heath, R.M. and Brown, J.M. (2005) Short-term endpoints of conventional versus laparoscopic-assisted surgery in patients with colorectal cancer (MRC CLASICC trial): Multicentre, randomised controlled trial. The Lancet, 365, 1718-1726. doi:10.1016/S0140-6736(05)66545-2

[3] Hazebroek, E.J. (2002) A randomized clinical trial comparing laparoscopic and open resection for colon cancer. Surgical Endoscopy, 16, 949-953. doi:10.1007/s00464-001-8165-z

[4] Nelson, H., Sargent, D.J., Wieand, S., Fleshman, J., Anvari, M., Stryker, S.J., Beart, R.W., Hellinger, M., Flanagan, R., Peters, W. and Ota, D. (2004) A Comparison of laparoscopically assisted and open colectomy for colon cancer: The clinical outcomes of surgical therapy study group. New England Journal of Medicine, 350, 2050-2059.

[5] Jayne, D., Thorpe, H., Copeland, J., Quirke, P., et al. (2010) Five-year follow-up of the Medical Research Council CLASICC trial of laparoscopically assisted versus open surgery for colorectal cancer. British Journal of Surgery, 97, 1638-1645. doi:10.1002/bjs.7160

[6] Schwenk, W., Haase, O., Neudecker, J., et al. (2005) Short term benefits for laparoscopic colorectal resection. Cochrane Database of Systematic Reviews, 3, Article ID: 003145.

[7] Fingerhut, A., Toufik, A., Chouillard, E., et al. (2007) Laparoscopic approach to colonic cancer: Critical appraisal of the literature. Digestive Disease, 25, 33-43. doi:10.1159/000099168

[8] Noel, J.K., Fahrbach, K., Estok, R., et al. (2007) Minimally invasive colorectal resection outcomes short-term comparison with open procedures. Journal of the American College of Surgeons, 204, 291-307. doi:10.1016/j.jamcollsurg.2006.10.002

[9] Person, B., Cera, S.M., Sands, D.R., Weiss, E.G., Vernava, A.M., Nogueras, J.J. and Wexner, S.D. (2007) Do elderly patients benefit from laparoscopic colorectal surgery? Surgical Endoscopy, 22, 401-405.

[10] Frasson, M., Braga, M., Vignali, A., Zuliani, W. and Di Carlo, V. (2008) Benefits of laparoscopic colorectal resection are more pronounced in elderly patients. Diseases of the Colon \& Rectum, 51, 296-300. doi:10.1007/s10350-007-9124-0

[11] De Santis, L. and Frigo, F. (2005) Laparoscopic colorectal surgery in the elderly. Acta BioMedica, 76, 24-26.

[12] Kurian, A.A., Suryadevara, S., Vaughn, D., Zebley, D.M., Hofmann, M., Kim, S. and Fassler, S.A. (2010) Laparoscopic colectomy in octogenarians and nonagenarians: A preferable option to open surgery? Journal of Surgical Education, 67, 161-166.

[13] Lian, L., Kalady, M., Geisler, D. and Kiran, R.P. (2010) 
Laparoscopic colectomy is safe and leads to a significantly shorter hospital stay for octogenarians. Surgical Endoscopy, 24, 2039-2043. doi:10.1007/s00464-010-0900-X

[14] Cheung, H.Y.S., Chung, C.C., Fung, J.T.K., Wong, J.C.H., Yau, K.K.K. and Li, M.K.W. (2007) Laparoscopic resection for colorectal cancer in octogenarians: Results in a decade. Diseases of the Colon \& Rectum, 50, 1905-1910. doi:10.1007/s10350-007-9070-X

[15] Vignali, A., Di Palo, S., Tamburini, A., Radaelli, G.,
Orsenigo, E. and Staudacher, C. (2005) Laparoscopic vs. open colectomies in octogenarians: A case-matched control study. Disesases of the Colon \& Rectum, 48, 20702075. doi:10.1007/s10350-005-0147-0

[16] Legner, V.J., Massarweh, N.N., Symons, R.G., McCormick, W.C. and Flum, D.R. (2009) The significance of discharge to skilled care after abdominopelvic surgery in older adults. Annals of Surgery, 249, 250-255. doi:10.1097/SLA.0b013e318195e12f 